\title{
Iridium-Catalyzed Asymmetric Hydroalkynylation of Unactivated Alkenes
}

\section{Key words}

\section{iridium catalysis}

hydroalkynylation

enantioselectivity<smiles>CCC(C)CCC(=O)N(P)P</smiles>

$$
\left.\right|_{\mathrm{H}} ^{\mathrm{TIPS}}
$$

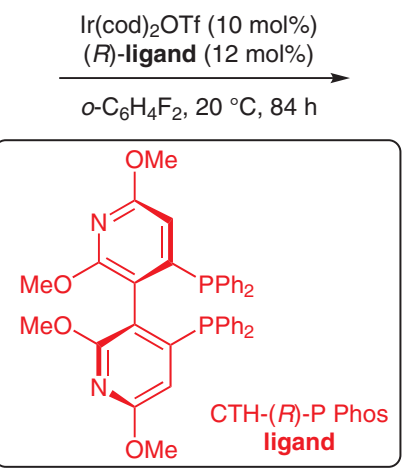<smiles>[R]N(C)C(=O)CCC(C)(C#CC(C)C)CCC</smiles>

Kinetic isoptope effect of alkene:<smiles>CCN(CC)C(=O)C/C=C(\C)CCBr</smiles><smiles>[2H]/C(CCBr)=C(/C)CC(=O)N([Tl])CC</smiles>

$k_{H} / k_{D}=0.90$<smiles>CCCC#C[C@](C)(CCBr)CCC(=O)N(CC)CC</smiles>

$\mathrm{R}^{1}=\mathrm{CH}_{2} \mathrm{CH}_{2} \mathrm{OMe}$<smiles>[2H]C(CC(=O)N(CC)CC)[C@](C)(C#CCCCC)CCBr</smiles>

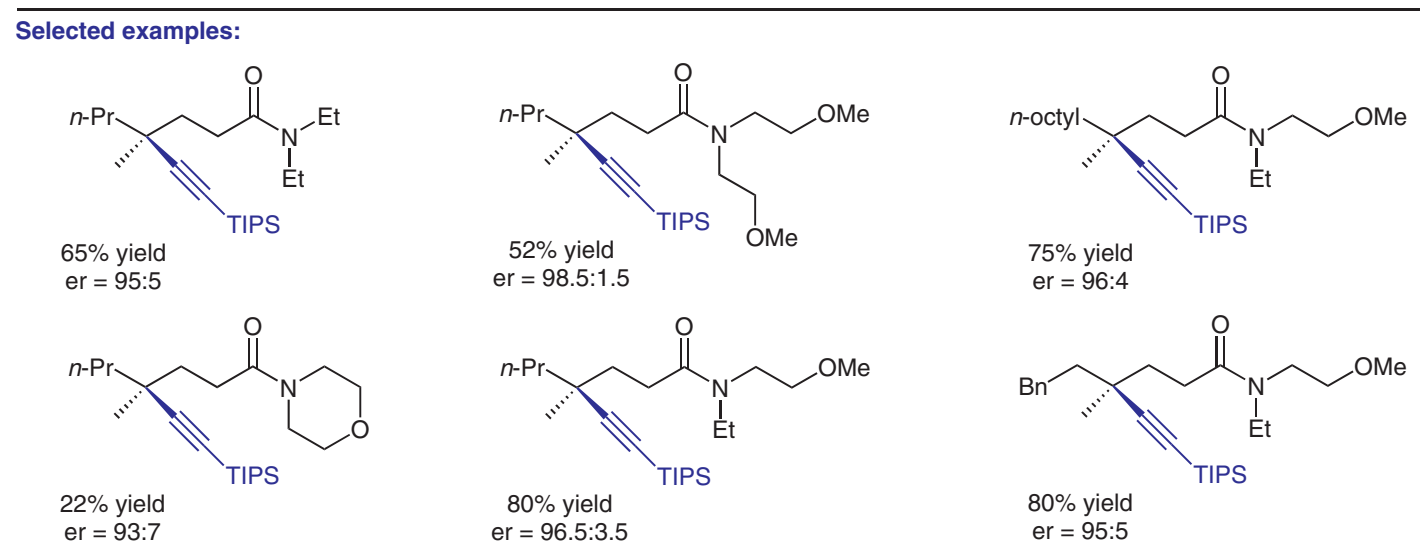

Significance: The authors have developed an enantioselective iridium-catalyzed hydroalkynylation reaction. The reaction transforms trisubstituted $\beta$, $\gamma$-unsaturated amides with excellent $\gamma$-selectivity, forming new alkyne-substituted acyclic quaternary carbon stereocenters.
Comment: The kinetic isotope experiments of the alkenes resulted in an inverse KIE; suggesting that the migratory insertion of the alkene is related to the turnover-limiting step. Notably, the authors propose that the selectivity arises from both a facial preference as well as an alkene isomerization process. 